\title{
O Processo de Design Digital: endereçando o desafio da multidisciplinaridade
}

\author{
Tânia S. M. Pinheiro, Ingrid Teixeira Monteiro, Danilo A. Felipe, Andréia Libório Sampaio \\ Universidade Federal do Ceará, Campus Quixadá. Quixadá, CE, Brasil. \\ taniapinheiro@ufc.br, ingrid@ufc.br, daniloafel@gmail.com, andreia.ufc@gmail.com
}

\begin{abstract}
Integrated Project is a type of course offered in the Digital Design program of the Federal University of Ceará, Quixadá Campus. It has the challenge of integrating into a single project some concepts from the areas of Computer Science, Design, Communication and Arts. For the interdisciplinarity to be productive, it was specified $\mathrm{PD}_{3}$ (Digital Disruptive Design Process), a design process based on HCI, Design, and Software Engineering methodologies. In this paper, we present the $\mathrm{PD}_{3}$ applied to the Integrated Project courses, describing how it has been used and evolved, as well as giving lessons learned.
\end{abstract}

\section{Author Keywords}

Design Process, Integrated Design, Digital Design, Multidisciplinarity, Applied Teaching.

\section{ACM Classification Keywords}

K.3.2. Computer and Information Science Education: Computer Science Education, Information Systems Education.

\section{INTRODUÇÃO}

O curso de bacharelado em Design Digital (DD) da Universidade Federal do Ceará está situado no Campus de Quixadá, um município do Estado do Ceará. Ele nasceu com a vocação de interagir com os cursos da área de computação, para complementá-los, e ser ele próprio um curso importante na criação, produção e gestão de negócios da tecnologia de informação e comunicação. Além disso, o curso é "orientado a IHC" [9], disponibilizando um conjunto vasto de disciplinas obrigatórias e optativas correlatas a esta área [12]. Por exemplo, são obrigatórias: Interação Humano-Computador, Avaliação da Interação, Projeto de Interface Web, Projeto de Interface para Dispositivos Móveis, Design e Inovação. E são optativas: User Experience, Engenharia Semiótica, Arquitetura da Informação, Ergonomia, e Prototipação Rápida.

O Projeto Pedagógico do Curso (PPC) [14] descreve o perfil do egresso como um profissional capaz de atuar na concepção, desenvolvimento e execução de projetos e de sistemas que envolvam informações digitais e visuais. Ele é capaz de produzir projetos e sistemas orquestrando

Permission to make digital or hard copies of all or part of this work for personal or classroom use is granted without fee provided that copies are not made or distributed for profit or commercial advantage and that copies bear this notice and the full citation on the first page. Copyrights for components of this work owned by others than the author(s) must be honored. Abstracting with credit is permitted. To copy otherwise, or republish, to post on servers or to redistribute to lists, requires prior specific permission and/or a fee. Copyright 2018 SBC.

IHC 2018, Anais Estendidos do XVII Simpósio Brasileiro sobre Fatores Humanos em Sistemas Computacionais

Outubro 22-26, 2018, Belém, Brasil

Workshop sobre Educação em IHC (WEIHC) informações visuais, artísticas, culturais e tecnológicas, sempre de forma contextualizada com aspectos históricos, traços culturais, potencialidades tecnológicas e características de desenvolvimento das comunidades.

Para formar este perfil de egresso, a matriz curricular do curso foi montada de forma a integrar disciplinas das áreas de Design, Computação, Comunicação e Artes, caracterizando-se como um curso multidisciplinar. Essa multidisciplinaridade é colocada em prática de forma mais direta com quatro disciplinas regulares e obrigatórias de Projeto Integrado, ofertadas entre o terceiro e o sexto semestre do curso. O objetivo dessas disciplinas é "fornecer ao aluno a oportunidade de pôr em prática, de forma integrada, os assuntos estudados em algumas disciplinas de semestres anteriores, bem como nas disciplinas cursadas simultaneamente com cada disciplina de projeto integrado" [14].

Surge então o desafio de integrar, num único projeto, conceitos multidisciplinares das diversas áreas do curso. Dentre outros, um dos principais desafios é a interseção entre alguns modelos utilizados nas áreas de IHC, Design e Engenharia de Software. Além disso, existem conceitos semelhantes com denominações diferentes. Outro desafio é a dificuldade para se estabelecer e manter a sincronização de conteúdos e a organização de um cronograma em comum entre as disciplinas envolvidas no projeto [14].

Diante dessas questões, sentimos a necessidade de sistematizar o processo de design implementado nas disciplinas de Projeto Integrado do Curso de Design Digital. O objetivo desse artigo é apresentar este processo e como ele foi construído. Mais especificamente, objetivamos (i) discutir e ressaltar o caráter multidisciplinar da disciplina, (ii) apresentar as etapas de execução do projeto de design digital e (iii) definir quais artefatos devem ser produzidos nesse processo.

Antes de descrever o processo, a seguir apresentaremos os principais conceitos e caraterísticas das disciplinas de Projeto Integrado. Em seguida, relatamos como o processo foi construído. Depois, apresentamos o $\mathrm{PD}_{3}-$ Processo de Design Digital Disruptivo, e, na seção seguinte, discutimos sobre o caráter "multi" versus "inter"disciplinar do Projeto Integrado. Por último, apresentamos as considerações finais deste trabalho. 
PROJETOS INTEGRADOS NO CURSO DESIGN DIGITAL As ementas das quatro disciplinas de projeto integrado têm o mesmo texto base: Projeto prático interdisciplinar cujo tema deverá ser ligado às disciplinas do [terceiro / quarto / quinto / sexto] semestre do curso, com ênfase [nos usuários / nos produtos / nos processos / em negócios e inovação] [14]. As quatro disciplinas ocorrem em duas aulas semanais, cada uma de duas horas, e são pré-requisitos entre si.

A Tabela 1 lista as disciplinas de Projeto Integrado onde, na segunda coluna, vê-se as disciplinas envolvidas. As disciplinas marcadas com um asterisco nos Projetos I e II são correquisitos deles, ou seja, para se matricular em Projeto I, o estudante precisa ter concluído ou estar matriculado em IHC e Semiótica. Este foi um mecanismo usado para induzir de forma mais direta a integração entre as disciplinas, considerando a ênfase de cada Projeto. Esta imposição foi realizada apenas nos dois primeiros Projetos, com o intuito de habituar os estudantes e os professores a esse formato, mas sem "amarrar" tanto as disciplinas, pois a impossibilidade de cursar uma das disciplinas que é correquisito geraria atrasos em cadeia, algo amenizado a partir do Projeto III (que não tem correquisitos).

\begin{tabular}{|c|c|}
\hline Projeto & Disciplinas envolvidas \\
\hline $\begin{array}{l}\text { Proj. Integrado I } \\
3^{\circ} \text { semestre } \\
\text { Foco: usuário }\end{array}$ & $\begin{array}{l}\text { Interação Humano-Computador }(\mathrm{IHC})(*) \\
\text { Semiótica }(*) \\
\text { Sociedade, culturas e tecnologias (SCT) }\end{array}$ \\
\hline $\begin{array}{l}\text { Proj. Integrado II } \\
4^{\circ} \text { semestre } \\
\text { Foco: produto }\end{array}$ & $\begin{array}{l}\text { Linguagens de marcação e scripts }(*) \\
\text { Direção de arte }(*) \\
\text { Avaliação de IHC }\end{array}$ \\
\hline $\begin{array}{l}\text { Proj. Integrado III } \\
5^{\circ} \text { semestre } \\
\text { Foco: processo }\end{array}$ & $\begin{array}{l}\text { Projeto de interfaces Web } \\
\text { Processos de criação }\end{array}$ \\
\hline $\begin{array}{l}\text { Proj. Integrado IV } \\
6^{\circ} \text { semestre } \\
\text { Foco: negócio }\end{array}$ & $\begin{array}{l}\text { Empreendedorismo } \\
\text { Design e inovação }\end{array}$ \\
\hline
\end{tabular}

Tabela 1. Disciplinas relacionadas aos Projetos Integrados

O Projeto Integrado I tem Semiótica e IHC como correquisitos, possui foco no usuário, e tem como produto final um protótipo de alguma solução digital, e os projetos são conduzidos seguindo o processo de design $\mathrm{PD}_{3}$ Processo de Design Digital Disruptivo, descrito neste artigo. Em Projeto Integrado II, utilizam o mesmo $\mathrm{PD}_{3}$, consolidando seu aprendizado, mas desta vez é preciso entregar a solução digital implementada ao final da disciplina. Projeto Integrado III, com foco no processo, adota processos de desenvolvimento diretamente da Engenharia de Software, ao qual as equipes de alunos agregam os elementos do processo $\mathrm{PD}_{3}$ cabíveis no tempo disponível. Por fim, Projeto Integrado IV, com foco em negócios, enfatiza o aprendizado de processos de negócio e, novamente, os alunos agregam os elementos do $\mathrm{PD}_{3}$ e de Engenharia de Software que considerarem prioritários.
Até o momento, foram ofertadas as seguintes disciplinas de Projeto Integrado (PI): PI I (2016.1, 2016.2, 2017.1, 2018.1); PI II (2016.2, 2017.2 e 2018.2); PI III (2017.1 e 2018.1) e PI IV (2017.2 e 2018.2). Para os estudantes repetentes, ofertou-se PI I em 2016.2 e PI II em 2017.1.

Para melhor compreender a complexidade destas disciplinas, podemos compará-la com os projetos integrados não curriculares, também conhecidos por projetos interdisciplinares. Nestes, o professor é livre para aderir ou não a projetos, quando busca integrar o conhecimento de suas disciplinas [10], ou mesmo independentes de disciplinas [2]. O escopo do projeto é definido a partir das relações interdisciplinares que os professores muitas vezes já possuem e, o "pensar como fazer" o projeto, sendo voluntário, ocorre (pelo menos inicialmente) no âmbito dos planos de ensino. Quando algo não dá certo ou se mostra inadequado, a discussão e ajustes ocorrem no âmbito das próprias disciplinas.

Já a versão de projeto integrado curricular é conduzida em torno de uma disciplina formal, que no caso do curso de Design Digital tem como conteúdo central uma metodologia projetual (ou processo) que serve de eixo para o desenvolvimento de projetos que integrem conhecimentos das demais disciplinas do mesmo semestre, em um total de quatro disciplinas. A adesão ao projeto é compulsória, e o seu escopo é definido pelo projeto do curso. Quando algo não dá certo ou se mostra inadequado, a discussão e ajustes precisam ocorrer no âmbito do colegiado do curso.

\section{METODOLOGIA}

Tratamos Projeto Integrado como equivalente ao que a literatura denomina projeto integrador [17], ateliê [16] ou oficina [4]. A pedagogia de trabalho é bem caracterizada por Schön [19], como um modelo educacional pautado em uma epistemologia da prática baseada na ação-reflexão. Denominando seus alunos como designers, Schön explica que estas disciplinas, "em geral, são organizadas em torno de projetos gerenciáveis de design, assumidos individual ou coletivamente, mais ou menos padronizados de forma similar a projetos tirados da prática real." [19].

Entendemos que a disciplina não pode ser completamente padronizada porque cada projeto é único em sua concepção e em processo de criação dos alunos. Mas demanda alguma padronização na forma de metodologia projetual, ou metodologia de design, a ser utilizada.

A metodologia de projetual utilizada nas disciplinas Projeto Integrado I e II, após receber contribuições de uma metodologia de gerência de projetos de software, passou a ser denominada Processo de Design Digital Disruptivo $\left(P D_{3}\right)$. Ao sistematizar a prática, os resultados acadêmicos têm melhorado, e os trabalhos começam a ser bem classificados ou premiados em concursos nacionais na área de design digital. Adicionalmente, os docentes envolvidos começam a ver caminhos para melhor integração de suas disciplinas com o Projeto Integrado. 
A concepção do $\mathrm{PD}_{3}$ é iterativa e a cada semestre recebe novos elementos. Foi inicialmente concebido no primeiro semestre letivo de 2016, a partir da experiência com metodologias projetuais de um professor que, além de ter experiência de mercado em Design, havia ministrado disciplinas equivalentes em curso de Design.

A partir da prática de 2016, o trabalho começou a ser sistematizado no início de 2017. No segundo semestre de 2017, começou a receber elementos de gerência de projetos do framework Scrum [20], trabalho concluído no meio do ano seguinte com a concepção do PiScrum [7], que define o "como" organizar a metodologia projetual original em um processo iterativo e incremental.

A partir daquele momento, considerou-se que a sistematização da prática havia concluído um primeiro ciclo de organização, tendo-se combinado a metodologia projetual com um cronograma de trabalho, e o resultado passou a ser denominado Processo de Design Digital Disruptivo $\left(\mathrm{PD}_{3}\right)$. Disruptivo aparece no sentido de visar o desenvolvimento de soluções inovadoras.

Em meados do primeiro semestre de 2018, um novo ciclo de elaboração do $\mathrm{PD}_{3}$ já havia sido iniciado, visando uma reflexão conceitual e crítica do que havia sido produzido. Buscando ser interdisciplinar, a reflexão precisa ser feita do ponto de vista de diferentes domínios do conhecimento, e os primeiros eleitos foram Design e IHC. O primeiro por ser a raiz da concepção do $\mathrm{PD}_{3}$, reflexão que será conduzida por uma aluna do próprio curso de Design Digital como trabalho de conclusão de curso. E priorizou-se IHC, dentre as demais disciplinas, porque foi a que recebeu mais atenção na integração com Projeto Integrado, mas os resultados ainda não são suficientes para a almejada interdisciplinaridade.

\section{O PROCESSO DE DESIGN DIGITAL DISRUPTIVO - PD 3}

$\mathrm{O}$ Projeto Integrado envolve muitas metodologias combinadas: (a) metodologia didática, pautada na açãoreflexão [19]; (b) metodologia projetual da área do Design; (c) processos de design de IHC; (d) orientações didáticas das demais disciplinas paralelas a ela; (e) além de alguma metodologia para gerenciar projetos.

Com a prática, chegamos à convergência de três abordagens de projeto para fundamentar o $\mathrm{PD}_{3}$, encontradas em: Brown [3], PiScrum [7] e Barbosa e Silva [1]. Iniciamos a descrição do $\mathrm{PD}_{3}$ a partir delas, seguindo suas relações ilustradas na Figura 1.

A primeira, definida por Brown [3, p. 60], trata as etapas do design como "espaços" às vezes sobrepostos: inspiração, "no qual insights são coletados de todas as formas possíveis"; idealização, "no qual esses insights são traduzidos em ideias"; e implementação, "no qual as melhores ideias são desenvolvidas em um plano de ação concreto e plenamente elaborado". Para chegar ao $\mathrm{PD}_{3}$, acrescentamos Briefing e Divulgação não tratados por Brown porque seu contexto é de um escritório de design que recebe briefings prontos dos clientes, e que passa para agências de publicidade tratarem da divulgação. Entretanto, embora o público usuário do $\mathrm{PD}_{3}$ não venha a se envolver diretamente nestas duas etapas, é importante considerar pelo menos a análise destas etapas em suas atividades.

Uma vez que já tínhamos alguma sistematização da prática, as dificuldades persistentes na condução dos projetos nos levaram à modelagem de um framework para gerência de projetos próprio para Projeto Integrado, que denominamos de PiScrum [7]: um híbrido entre Scrum (ênfase na entrega de produto) [20] e eduScrum (ênfase em aprendizagem) [5]. Com o PiScrum, a metodologia projetual passa a ter um ritmo, bem como ferramentas que proporcionam transparência do andamento dos trabalhos, o que possibilita o acompanhamento dos projetos por qualquer dos professores das disciplinas paralelas. Podemos começar a dizer que se trata de um novo processo, e surge o nome Processo em Design Digital Disruptivo $\left(\mathrm{PD}_{3}\right)$.

A partir do PiScrum, o processo foi organizado em cinco ciclos de desenvolvimento (sprints), que proporcionam o desenvolvimento iterativo e incremental preconizado pelo Scrum, ilustrados na coluna ITERAÇÕES da Figura 1. No caso das disciplinas de Projeto Integrado I e II, as sprints possuem três semanas de duração. A cada "espaço" definido por Brown, tem-se uma iteração no $\mathrm{PD}_{3}$.

Por fim, partimos de Barbosa e Silva [1] para sistematizar o que acontece em cada iteração do $\mathrm{PD}_{3}$. Em sua revisão de literatura, os autores identificaram que o processo de design segue, iterativamente, três atividades gerais: análise, síntese e avaliação. Uma vez ditas iterativas, aplicamos estas três atividades a cada uma das iterações do $\mathrm{PD}_{3}$, chegando ao seu formato final (Figura 1). Tal configuração encontrou fundamento em Lawson [11], um dos textos citados por [1], ao descrever análise/síntese/avaliação também aplicadas a cada fase iterativa de um processo geral de design.

Assim como [1, 11, 13], também entendemos que um processo de design pode não ocorrer exatamente linear: enquanto se testa diferentes versões de protótipos, por exemplo, pode-se perceber ser mais interessante rever todo o conceito do produto e mesmo o seu público-alvo; quando se começa uma síntese, pode-se perceber que a análise precisa ser retomada para completar informações.

Análise envolve conhecer os elementos envolvidos pessoas, artefatos e processos - buscando padrões nas informações disponíveis [1, 11]. A Síntese consiste em avançar para uma situação futura de se gerar uma solução, com novas propostas, a serem avaliadas [11]; entendemos que é na síntese que se percebe a presença de novos "incrementos" ao projeto. Na avaliação portanto, se obtém um feedback do que foi elaborado na síntese [1].

A Figura 1 ilustra as cinco iterações (ou Sprints) do $\mathrm{PD}_{3}$, com, à exceção da última, suas respectivas atividades análise, síntese e avaliação, totalizando 14 etapas. 


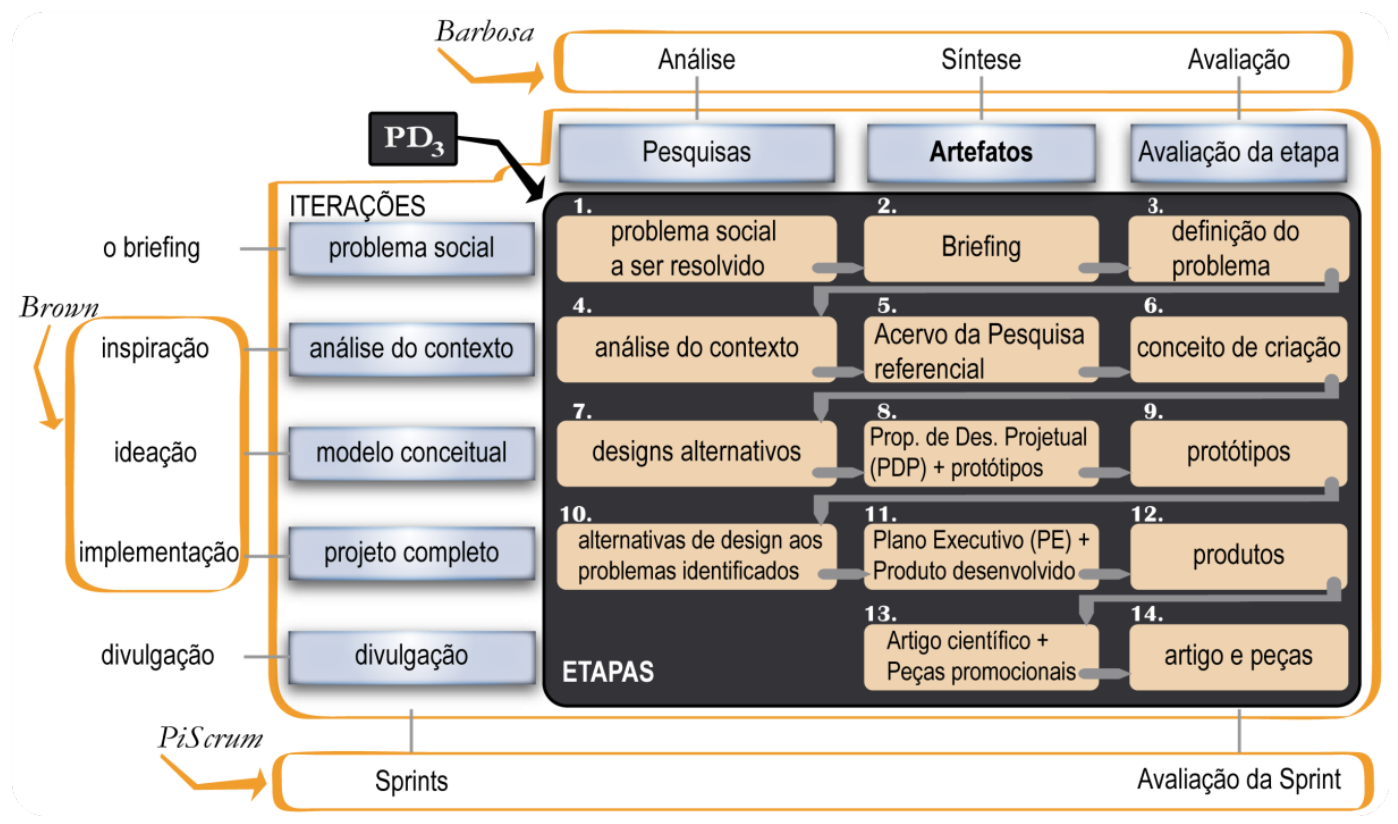

Figura 1. Visão conceitual do PD3

Apesar de "artefato" não ser exatamente uma "atividade de síntese", foi assim considerado porque processos de design são muitas vezes descritos na forma dos produtos resultantes de suas etapas, e não de descrição de atividades realizadas. Tal característica é encontrada no processo de design descrito por [13], e no levantamento de processos de design feitos por [11]. A Figura 2 descreve cada artefato e o conjunto de atividades envolvidas em cada um deles.

$\mathrm{Na}$ sprint "problema social", o $\mathrm{PD}_{3}$ começa analisando "problema social a ser resolvido", em seguida, sintetizandoo na forma de um Briefing, o qual é avaliado quanto a clareza e pertinência da definição do problema. A segunda sprint se inicia com a análise de contexto, seguida da organização de todo o acervo da pesquisa referencial que conduz a uma síntese, esta materializada no conceito de criação do produto/solução (um dos itens do PDP, o artefato seguinte); em seguida se avalia o conceito de criação.

A terceira sprint, "modelo conceitual", inicia a análise de designs alternativos, uma forma de pesquisa experimental; depois são construídos o PDP (ver Figura 2) e protótipos, finalizando-se com avaliações iniciais dos protótipos. $\mathrm{Na}$ quarta sprint, "projeto completo", é feita uma nova análise da solução baseado no feedback da avaliação da sprint anterior, seguida de uma síntese em que se produz novos incrementos, representada pelo Plano Executivo; o produto então é desenvolvido, e depois avaliado. Em Projeto I, "desenvolver" significa fazer protótipo funcional, e em Projeto II implementar a solução. A última sprint é focada na divulgação, em que a síntese crítica de todo trabalho é materializada em um artigo científico, e se produz peças de divulgação da solução, podendo ainda serem avaliadas.

A Figura 2 apresenta todos os artefatos gerados no $\mathrm{PD}_{3}$. $\mathrm{O}$ Briefing descreve o problema a ser resolvido [13]. No meio corporativo, costuma ser fornecido pelo cliente [3], mas, em nosso meio educacional, ele é elaborado nos primeiros contatos com o cliente. Denominamos por cliente pessoas da comunidade voluntárias em participar do projeto, que compartilham seus problemas reais. Ao longo do projeto, em especial nas reuniões de avaliação de cada etapa (sprint), esse papel é representado pelo professor.

\begin{tabular}{|c|c|}
\hline \multicolumn{2}{|c|}{ Artefatos } \\
\hline & Acervo da Pesquisa Referencial \\
\hline diretrizes estabelecidas pelo cliente & \multirow{2}{*}{$\begin{array}{l}\text { Pesquisas: teórica, iconográfica, de campo e } \\
\text { de situaçoes concorrentes. }\end{array}$} \\
\hline \multirow{3}{*}{$\begin{array}{l}\text { 1. Identificação, 2. Descrição do produto/serviço, } \\
\text { 3. Projeto: } 3.1 \text { Delimitaçăo do contexto, problema } \\
\text { e oportunidade; } 3.2 \text {. Imagem do Cliente e principais } \\
\text { diferenciais; } 3.3 \text { Concorrência, } 3.4 \text { Público-alvo } \\
\text { e posicionamento de mercado. }\end{array}$} & \\
\hline & Artigo cientifico em formato acadêmico \\
\hline & $\begin{array}{l}\text { Análise crítica do processo de desenvolvimento } \\
\text { e do resultado descrito no Plano Executivo. }\end{array}$ \\
\hline $\begin{array}{l}\text { Proposta de Desenvolvimento Projetual (PDP) } \\
\text { estudo conceitual do projeto }\end{array}$ & $\begin{array}{l}\text { Plano Executivo (PE) } \\
\text { documentação completa do projeto de design }\end{array}$ \\
\hline \multirow{6}{*}{$\begin{array}{l}\text { 1. Identificação/apresentação. } \\
\text { 2. Problema: objetivos (para clientes), público-alvo, } \\
\text { situaçães concorrentes. } \\
\text { 3. Solução: estratégia de design, } \\
\text { conceito de criação, soluçãa de design } \\
\text { 4. Projeto: marca/identidade visual, paleta de cores } \\
\text { e harmonia cromática, elementos visuais/linguagem } \\
\text { gráfica, tipografia, projetos especificos preliminares } \\
\text { (informação, interface, navegação, interação), } \\
\text { storyboards. } \\
\text { 5. Materiais e tecnologias; breve descrição. } \\
\text { 6. Plano de divulgação: breve descrição. }\end{array}$} & 1. Identificação/apresentação. \\
\hline & $\begin{array}{l}\text { 2. Problema: objetivos (para desenvolvedores), } \\
\text { público-alvo, situacỗes concorrentes. }\end{array}$ \\
\hline & $\begin{array}{l}\text { 3. Solução: equivalente ao PDP. } \\
\text { 4. Projeto: mesmos itens do PDP, porém com }\end{array}$ \\
\hline & $\begin{array}{l}\text { os projetos especificos completos. } \\
\text { 5. Materiais e tecnologias: detalhado. } \\
\text { 6. Plano de divulgaçâo: detalhado. }\end{array}$ \\
\hline & Peças de Divulgação do projeto \\
\hline & $\begin{array}{l}\text { Cartaz, banner digital, embalagem, } \\
\text { video promocional, brindes. }\end{array}$ \\
\hline
\end{tabular}

Figura 2. Artefatos do $\mathrm{PD}_{3}$

O Acervo da pesquisa referencial é o conjunto de documentos coletados do contexto do usuário, através de pesquisas teóricas, iconográficas ou de campo. Podem ser leis, fotos, entrevistas, anotações etc. O PDP - Proposta de Desenvolvimento Projetual contém as diretrizes conceituais e visuais que foram concebidas como solução para os principais aspectos do problema [13], incluindo apresentação, problema, solução, projeto, materiais e tecnologias utilizadas e plano de divulgação. O Plano Executivo, de certo modo um detalhamento do PDP, contém a documentação necessária à execução 
(implementação) completa do projeto. No Artigo Científico é apresentada uma análise crítica do processo de desenvolvimento e do produto final. Por fim, as Peças de divulgação de projeto podem ser desde uma embalagem do produto, até um cartaz ou vídeo promocional.

O trabalho de sistematização dos Projetos Integrados I e II busca prover condições para a efetiva interdisciplinaridade com suas disciplinas paralelas. $\mathrm{Na}$ seção a seguir, discutimos nosso entendimento de interdisciplinaridade, e como se percebe a atual relação de Projeto Integrado I com sua disciplina paralela IHC.

\section{PROJETO INTEGRADO E IHC: MULTI OU INTERDISCIPLINARIDADE?}

Apesar das relações interdisciplinares estarem começando a ser percebidas pelos docentes, nem sempre os alunos as percebiam [7]. Por exemplo, no início da última edição de Projeto I, observou-se que os alunos não estavam percebendo que uma determinada "pesquisa referencial de campo" proposta em Projeto I, era equivalente a uma "análise de tarefas, usuários e funções" propostas na mesma época em um dos processos descritos na disciplina de IHC (Estrela) [1]. Como consequência, trabalharam mais do que o necessário, mostrando partes da pesquisa de campo para uma disciplina e partes em outra, sem um método claro. $\mathrm{O}$ esperado era que a referida pesquisa de campo fosse entregue completa nas duas disciplinas, para usos específicos em cada uma delas.

Foi observado que seria necessário "traduzir" para o Projeto Integrado o que se esperava, por exemplo, da questão "o que avaliar?" tratada na disciplina de IHC [1]. Enquanto as técnicas de coleta de dados caracterizadas nos "métodos de investigação" (entrevista, brainstorming, focus group, questionários etc.) só são vistas tradicionalmente ao final da disciplina de IHC, enfatizando "quais aspectos do sistema devem ser avaliados?", em Projeto I a demanda vem no início do semestre para se analisar "quais os problemas do clientes, bem como seus valores tecnológicos, estéticos e culturais?". Para endereçar essa questão, as técnicas de coleta de dados foram deslocadas bem para o início do semestre justamente para dar suporte à análise de contexto (pesquisa de campo) do Projeto Integrado.

Os professores de ambas as disciplinas perceberam que não há muita dificuldade na integração, mas tal compreensão não chegou aos alunos, que foram a campo com as questões mais eminentes em IHC, mas não coletaram algumos dos dados previstos na metodologia de design em Projeto I.

Estudadas as dificuldades de integração de Projeto Integrado com as quatro disciplinas ofertadas em paralelo a ela, chega-se ao seguinte questionamento: a relação disciplinar entre elas é mesmo interdisciplinar? Podemos mesmo dizer que o Projeto Integrado é interdisciplinar? Qual a diferença entre multi e interdisciplinaridade?

A área de IHC é reconhecidamente multidisciplinar. A Comissão Especial de Interação Humano-Computador (CE-
IHC) da Sociedade Brasileira de Computação (SBC) lista como disciplinas de interesse da área: Ciência da Computação, Artes, Design, Ergonomia, Psicologia, Sociologia, Semiótica e Linguística [18]. Alinhado a essa visão, a ACM SIGCHI propôs um currículo para cursos de computação orientados a uma formação básica em IHC, sugerindo a inserção de disciplinas de quatro áreas Interação Humano-Computador; Psicologia e Ciência Cognitiva; Mídia; e Design - totalizando 23 disciplinas, além das comuns para a formação em computação [9].

A multidisciplinaridade ocorre quando diferentes domínios de conhecimento $\mathrm{D}_{1}$ e $\mathrm{D}_{2}$ se encontram mas sem ampliar, no contato com o outro, sua própria forma de ver o objeto do conhecimento. A interdisciplinaridade, por sua vez, se relaciona a uma busca por integrar as diferentes formas de ver os objetos do conhecimento próprias de cada $D_{n}$ (Domínio de Conhecimento). Não almeja ser uma ciência das ciências, em especial porque pretende preservar os diferentes pontos de vista para não se recair em uma situação de unidisciplinaridade [6].

Quando a forma de ver o mundo começa a mudar no contato com outro domínio de conhecimento, se começa a ter a interdisciplinaridade: $D_{1}$ inclui em sua descrição de mundo parte da visão de $\mathrm{D}_{2}$ (e vice-versa). Mas como ocorre na prática? Dizer que $\mathrm{D}_{1}$ consegue descrever o mundo em parte como D2, significa dizer que $\mathrm{D}_{1}$ começa a absorver parte do domínio linguístico de $\mathrm{D}_{2}$. Desta forma, o início de um trabalho interdisciplinar demanda $o$ "estabelecimento de conceitos-chave para facilitar a comunicação entre os membros da equipe" [6]. É esta delimitação conceitual, pelo menos inicial, que temos começado a traçar para chegar à interdisciplinaridade entre IHC e Projeto Integrado.

Furtado [8] exemplifica interdisciplinaridade ao mostrar como a visão combinada da psicologia ambiental $\left(\mathrm{D}_{1}\right)$ integrada à visão do Design Sustentável $\left(\mathrm{D}_{2}\right)$ pode contribuir para o design de sistemas interativos sustentáveis, em sua fase de elicitação de requisitos. O trabalho elabora um quadro conceitual interrelacionando o significado, para cada domínio, das categorias indivíduo, artefato, atividade, contexto e interação.

A interdisciplinaridade ocorrerá caso a caso, porque ela é um encontro entre pessoas mais do que um encontro de conteúdos. O domínio linguístico falado por uma pessoa não é só da sua área de conhecimento, mas uma bagagem de uma história de vida. A interdisciplinaridade se constrói no encontro e na prática.

\section{CONSIDERAÇÕES FINAIS}

Processos de design tem "começo, meio e fim" e recursos limitados. No caso de uma disciplina acadêmica, o principal recurso é o tempo, absolutamente pré-definido. A organização de um processo de design em etapas bem definidas (sprints), explicitamente iterativa e incremental, possibilitou mais clareza quanto ao necessário equilíbrio 
entre o que era desejável para as soluções, e o que era possível com o recurso de tempo disponível.

Entretanto, o processo de design mostrou-se insuficiente para promover a boa integração com as disciplinas, mesmo no caso de IHC que já tinha seu planejamento didático alinhado com o planejamento do Projeto Integrado I. Temos dito que a complexidade da disciplina está na sincronização de conteúdos [15], o que foi bem amenizado com o $\mathrm{PD}_{3}$ que proporcionou melhores condições para a sincronização de cronogramas. As condições de trabalho melhoraram muito, mas ainda há o que avançar. Um novo caminho aberto foi o estudo sobre interdisciplinaridade, que explicou o motivo das "traduções" de uma disciplina para a outra terem gerado algum resultado positivo: é preciso dar atenção ao domínio linguístico utilizado nos Projetos Integrados.

A interdisciplinaridade se aprende fazendo [6]. Com a prática de projetos integrados, junto a estudo teórico em interdisciplinaridade, se começa a ter compreensões iniciais do "como" ser, de fato, interdisciplinar no ensino de IHC.

\section{AGRADECIMENTOS}

Agradecemos aos professores José Neto de Faria, idealizador da metodologia de design da qual se origina o $\mathrm{PD}_{3}$, João Vilnei de Oliveira Filho, Valdemir Pereira de Queiroz Neto e Paulo Victor Barbosa de Sousa que, junto com as duas primeiras autoras, formam o conjunto de professores do terceiro semestre do curso de Design Digital e se dispõem a encontrar caminhos para tornar o Projeto Integrado I de fato uma jornada interdisciplinar.

\section{REFERÊNCIAS}

1. Simone D. J. Barbosa and Bruno S. Silva. 2010. Interação Humano- Computador. Editora Elsevier.

2. Paula Batistello, Katiane L. Balzan and Alice. T. C. Pereira. 2016. Integração no ensino de arquitetura e urbanismo: experiências com ateliês verticais. Revista Projetar: Projeto e Percepção do Ambiente, Natal, v. 1, n. 3, p. 47-59, dez.

3. Tim Brown. 2010. Design Thinking. Editora Campus.

4. Emanuel F. Coutinho, George A. M. Gomes and Antônio J. M. L. Júnior. 2016. Applying design thinking in disciplines of systems development. In Proceedings on Euro American Conference on Telematics and Information Systems (EATIS), 8., 2016, Cartagena. IEEE. http://doi.org/10.1109/EATIS.2016.7520123.

5. Arno Delhij, Rini van Solingen and Willy Wijnands. $\mathrm{O}$ guia eduScrum: as regras do jogo. 2016. Retrieved October, 312017 from http://eduscrum.nl/en/file/CKF iles/O_guia_eduScrum.pdf.

6. Ivani C. A. Fazenda. 2012. Interdisciplinaridade: história, teoria e pesquisa. 18 ed. Papirus.

7. Danilo Almeida Felipe. Adaptação do framework Scrum em disciplinas iniciais de projeto integrado. Monografia de Graduação, UFC, Quixadá, CE, 2018.
8. Elizabeth Furtado and Thais Kampf. 2010. A psicologia ambiental no projeto sustentável de sistemas interativos. In Proceedings of the HCI Education Workshop (WEIHC 2010) - 9th Brazilian Symposium on Human Factors in Computing System.

9. Thomas T. Hewett, Ronald Baecker, Stuart Card, Tom Carey, Jean Gasen, Marilyn Mantei, Gary Perlman, Gary Strong and William Verplank. 1992. ACM SIGCHI Curricula for Human-Computer Interaction. New York: ACM. Retrieved May 02, 2018 from https://dl.acm.org/citation.cfm?id=2594128

10. Ana C. A. Holanda and Marcelo A. Bairral. 2017. Possibilidades do E-Learning em Projetos Interdisciplinares no IFAC. In: Congresso Brasileiro de Informática na Educação, 6., 2017, Recife. Anais dos Workshops. Recife: SBC, 2017. p. 409-413. DOI: 10.5753/cbie.wcbie.2017.409.

11. Bryan Lawson. 2005. How Designers Think - the design process demystified. 4 ed. Elsevier.

12. Ecivaldo S. Matos. 2013. Integração curricular por meio da prática de ensino interdisciplinar em IHC. In Proceedings of the IV HCI education workshop (WEIHC 2013) - 12th Brazilian Symposium on Human Factors in Computing System.

13. Chico H. Melo. 2005. Signofobia. Editora Rosari

14. Ingrid T. Monteiro (ed.). Projeto Pedagógico do Curso Design Digital - Revisão 2018. Universidade Federal do Ceará: 2018. Documento interno.

15. Ingrid T. Monteiro and A. L. Sampaio. 2015. A formação em IHC no curso de Design Digital da Universidade Federal do Ceará. In Proceedings of the HCI Education Worshop - Brazilian Symposium on Human Factors in Computing System.

16. Clara O. M. Rodrigues and Verônica M. F. Lima. 2017. A Bitácora como ferramenta de ensino-aprendizagem na arquitetura. Revista Projetar: Projeto e Percepção do Ambiente, Natal, v. 2, n. 3, p. 47-60, dez.

17. Maria C. C. Santos and Sérgio R. Barra. 2012. O Projeto Integrador como ferramenta de construção de habilidades e competências no ensino de engenharia e tecnologia. In Congresso Brasileiro de Educação em Engenharia (COBENGE), 11. Belém. Abenge.

18. SBC. Sociedade Brasileira de Computação. 2018. Site da Comissão Especial de Interação HumanoComputador (CEIHC): http://comissoes.sbc.org.br/ceihc/

19. Donald A. Schön. 2000. Educando o profissional reflexivo. Artes Médicas Editora.

20. Ken Schwaber and Jeff Sutherland. Guia do Scrum. 2017. Retrieved July, 2018 from https://www.scrumguides.org/docs/scrumguide/v2017/ 2017-Scrum-Guide-Portuguese-Brazilian.pdf 